\title{
Art Saves Lives
}

\author{
Connie Nugent MLS
}

Art saves lives.

Wait. What? Physicians save lives. Medical research saves lives. Pharmaceuticals save lives. Advanced technology saves lives. How does art save lives?

While school districts across the United States decrease or eliminate classes in art and music in favor of reading and math classes that meet state testing requirements, many medical schools include art classes in their curricula. What is the connection between art and medicine? How can art analysis benefit medical students, residents, fellows, and attending physicians and, ultimately, their patients?

Over 20 years ago, Dr. Irwin Braverman, a dermatologist at Yale, noticed that medical students often jumped to conclusions or relied overmuch on technology when developing a diagnosis instead of depending on their own observations. ${ }^{1}$ Reasoning that exposure to art could sharpen students' observational skills, Dr. Braverman piloted a course in analyzing art; students spent time in museums then described objectively what they saw in paintings. His students' diagnostic skills improved by ten percent.

When viewing Edward Hopper's painting The Automat (1927), students might consider the figure of the woman, her posture, her clothing, her facial expression, her actions. They would look at the actual composition of the painting, the position of the table, the point of view of the observer, the time of day. Discussing their observations, they might point out that the woman is dressed for cooler weather, that her empty plate suggests that she has been alone at

Corresponding author: Connie Nugent

Contact Information: Connie.nugent1@gmail.com DOI: 10.12746/swrccc.v8i33.651

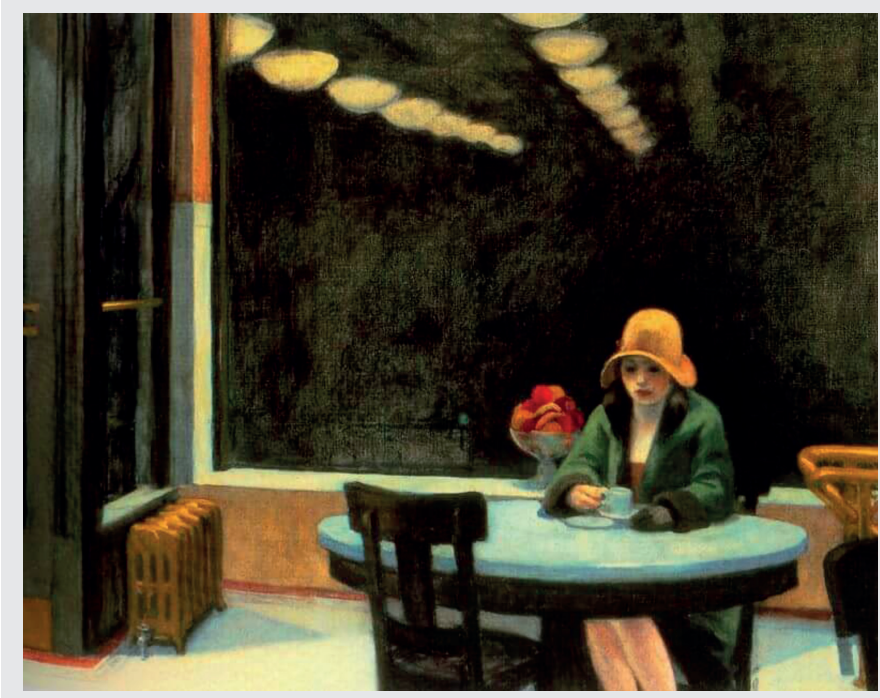

Edward Hopper. The Automat. 1927. The Des Moines Art Center, Des Moines, Iowa.

the table for some time, that her downcast head and the downturned brim of her hat indicate loneliness or depression. The bright lights reflected in the window behind her contrast with the inky night; only pale shadows are seen outside, which intensifies her solitary position. The off center table anchors the lower right side of the painting; it appears to be near the door of the automat, surely an undesirable location. The bright red flowers in the vase behind the woman contrast with and only emphasize the melancholy mood. When later observing a patient in the exam room, a medical student might well remember that these kinds of details can reveal much about the patient and could aid in developing a diagnosis.

Other medical schools began including art appreciation courses in their curricula. Harvard internist Dr. Joel Katz developed a course in 2003 called Training the Eye: Improving the Art of Physical Diagnosis, in which first and second year medical students "study concepts ranging from symmetry and 
texture to form and motion." For example, students might study a sculpture from several angles, noting the differences in shading or texture. Then, when examining a pulmonary patient in different positions, they observe the changes in breathing patterns.

Artist Anna Willieme believes in art as a teaching tool, "I was always fascinated, as an artist, with the ways that art could help me observe more," ${ }^{2}$ and designed a course for medical students and physicians"Observation and Uncertainty in Art and Medicine." She maintains that the "art museum is a laboratory" that can hone perceptual skills. After examining a painting or sketching a sculpture, students discuss their observations, seeing how others' interpretations may have differed. Willieme suggests that these observational skills can transfer to the exam room, as students notice subtle details about the patient and/or the family that would aid in diagnosis.

Medical students who examine Pieter Brueghel the Elder's painting Landscape with the Fall of Icarus (1560) may wonder Where's Icarus? The title says it's the fall of Icarus, but where is he? Precisely the point.

This painting reflects one interpretation of the myth of Daedalus and Icarus. Escaping in flight from the island where they were exiled, Daedalus warned his son not to fly too close to the sun since the heat would surely melt the wax holding his wings' feathers.

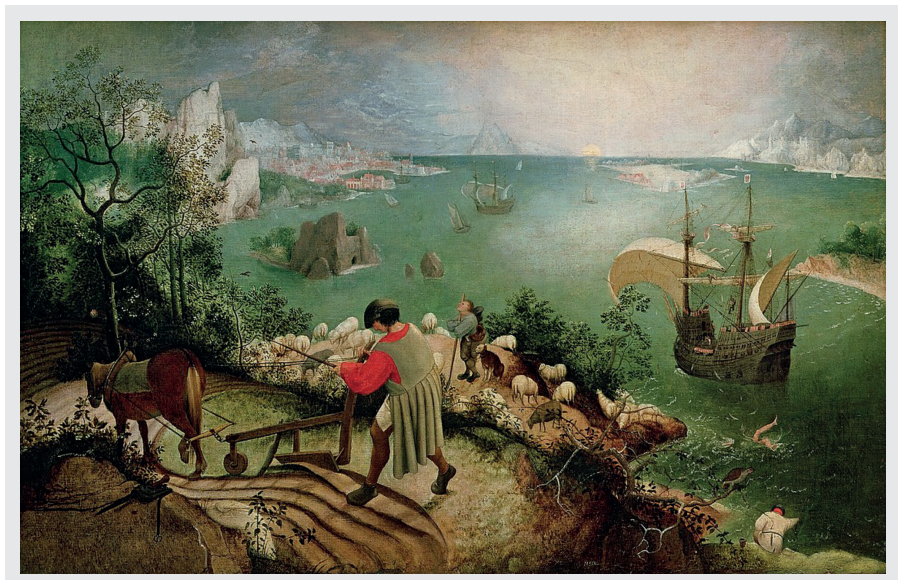

Pieter Brueghel the Elder. Landscape with the Fall of Icarus. c.1560. Royal Museums of Fine Arts of Belgium, Brussels.
Of course, young Icarus could not resist this exhilaration, his wings fell apart, and he plunged to his death in the sea. Rather than being the focal point of the painting, however, Icarus is seen only in the lower right corner, and then only his flailing legs appear. Others don't seem to notice the tragedy, suggesting an indifference to other points of view. The farmer continues plowing his field, the shepherd tends his flock, the sailors man the sails, life goes on. Even the nearby fisherman has his head lowered toward the water, not toward the splash.

According to Brueghel
when Icarus fell
it was spring
a farmer was ploughing
his field
the whole pageantry
of the year was
awake tingling
near
the edge of the sea
concerned
with itself
sweating in the sun
that melted
the wings' wax
unsignificantly
off the coast
there was
a splash quite unnoticed
this was
Icarus drowning

In his commentary about Brueghel's painting, poet William Carlos Williams (1883-1963) points out the irony of the season-the "pageantry" of spring implies a joyous time of rebirth, of planting seeds, of lambing. As others focus on only their interests, an "unsignificant" splash occurs, and Icarus dies. Both Brueghel's painting and Williams's poem present different points of view of a person's difficulty; considering alternatives is a skill that would benefit medical students. A survey of medical students enrolled in Anna Willieme's course from 2014-2017 revealed that analyzing art 
improved their "reflection-their ability to understand a situation from different points of view, to empathize with another person's dilemma, and to acknowledge different ways of thinking."

Dr. Salvatore Mangione et al reported that the medical profession has a burnout rate of over $50 \%$, with students and physicians often feeling anxious and depressed, resulting in decreased empathy for patients. He and his colleagues designed an online survey of medical students in five medical schools in the United States 2014-15 that revealed that "exposure to the humanities was significantly correlated with positive personal qualities" ${ }^{4}$ which in turn could reduce physician burnout. Tulane University School of Medicine professor Dr. Marc Kahn explained that "we were able to show a reasonably robust correlation between the amount of time students spent in the arts and their scores on validated assessments of empathy, tolerance of ambiguity, [and] wisdom . . . even in medical schools we see students burn out, so this correlation, we think, is important." ${ }^{5}$ Mangione maintains that "if we wish to create wiser, more tolerant, empathetic, and resilient physicians, we might want to reintegrate the humanities in medical education."

Recently, Marian University College of Osteopathic Medicine cardiologist Dr. Daniel Gelfman viewed Michelangelo's David in the Accademia Gallery in Florence, Italy, and noticed a bulging neck vein on the sculpture. Gelfman was puzzled that the sculptor would have included such a prominent indicator of possible heart disease on a statue of an otherwise robust young man. Further study of Michelangelo's works revealed similar depictions of anatomical signs of a variety of health conditions. In an article in JAMA Cardiology, Gelfman supported studying artworks to improve physicians' diagnostic skills. ${ }^{6} \mathrm{He}$ and Associate Professor of Art History Jamie Higgs began teaching a course for first year medical students designed to stimulate visual thinking strategies. After viewing an artwork, students are asked to provide evidence and reasoning for their opinions. Higgs suggests that a group discussion "helps people understand ambiguity and enhances their observational skills, critical thinking, ability to listen to others, and empathy for someone else's point of view."



http://www.accademia.org/explore-museum/artworks/ michelangelos-david/

Analyzing artworks can strengthen the observational and diagnostic skills of medical students and physicians, but studying literature can be just as useful. In an article in Literature and Medicine, Woods Nash proposes that reading fiction "can expand doctors' worldviews and make them more attuned to the dilemmas real patients face."8 Students in medical and nursing schools often discuss ethical case studies to determine if the medical personnel erred and/ or what kind of decision should be made in a certain situation. Nash argues that case studies are typically brief and omit "most of the nuance and motivation for characters' behavior... which limits the usefulness of case studies." ${ }^{\prime \prime}$ In Nash's classes, students read longer works of fiction that concern ethical dilemmas and summarize them. In group discussions, students compare summaries and how they differ in their 
assumptions or in the details left in or omitted. Nash points out that case studies, or summaries, are efficient, but that "doctors spend far too little time really listening to patients and trying to appreciate the depths of their patients' problems." ${ }^{8} \mathrm{He}$ maintains that "Good short stories are far more effective means of teaching students and health-care professionals to wrestle with the mess, to pay attention to narrative perspective and detail, and to become more comfortable with ambiguity." ${ }^{8}$ The Department of Internal Medicine at Texas Tech University Health Sciences Center, Lubbock, TX, sponsors a Medicine in the Humanities course for residents and fellows. Internist Dr. Michael Phy and Professor of Classical and Comparative Literature Dr. Peter Barta lead discussions of literature and film with medical themes. Dr. Barta chooses material that is "directly relevant to training in medical communication, especially with a view to the empathic management of vulnerable people."

Amy Herman calls the ability to understand how to look slowly and carefully "visual intelligence." ${ }^{10}$ She claims that "art is a powerful tool that engages both sight and insight and reframes our understanding" 10 and that the talent lies in asking questions to gain the information that is needed. When teaching visual intelligence through art, Herman practices four As: Assess the situation, Analyze it, Articulate it in some form of communication, and Act to make a decision. Extrapolating this method, she suggests that medical personnel, when entering a patient's room, simply look around. What might the doctor/nurse/medical student see? Are there objects that connect the patient to the outside world? Cards? Balloons? Special blankets? A conversation with the patient can be more meaningful when keeping these connections in mind. Herman maintains that employing visual intelligence when looking at art "helps people across the professional spectrum . . . to articulate what is absent and to be able to inspire creativity and innovation ... . [and] to forge human connections." 10

art is

when a human

tells

another human

what it is

to be human ${ }^{11}$
Keywords: art, observation, painting

Article citation: Nugent C. Art Saves Lives. The Southwest Respiratory and Critical Care Chronicles 2020;8(33):74-77

From: Department of Internal Medicine, Texas Tech University Health Sciences Center, Lubbock, Texas

Submitted: $1 / 22 / 2020$

Accepted: $1 / 24 / 2020$

Reviewer: Gilbert Berdine MD

Conflicts of interest: none

This work is licensed under a Creative Commons Attribution-ShareAlike 4.0 International License.

\section{REFERENCES}

1. Khullar D. What doctors can learn from looking at art. $N Y$ Times. Dec. 22, 2016. https://www.nytimes.com/2016/12/22/ well/live/what-doctors-can-learn-from-looking-at-art.html Accessed 01/05/2020

2. Lesser C. Looking at art could help med students become better doctors. Aug 21, 2017. https://www.artsy.net/article/ artsy-editorial-art-help-med-students-better-doctors

3. Williams W. "Landscape with the Fall of Icarus." 1962. https://poets.org/poem/landscape-fall-icarus

4. Mangione S, Chakraborti C, Staltari G, et al. Medical students' exposure to the humanities correlates with positive personal qualities and reduced burnout: a multi-institutional US survey. J Gen Intern Med. 2018;33(5):628-34.

5. Lesser C. Study finds med students who make time for art have more empathy. Jan 30, 2018. https://www.artsy.net/ article/artsy-editorial-med-students-time-art-empathy

6. Gelfman DM. The David Sign. JAMA Cardiol. 2020;5(2):124-125.

7. Rudavsky S, Bongiovanni D. How an Indiana doctor found a medical mystery in Michelangelo's 'David.' https:// www.thecalifornian.com/story/news/health/2020/01/16/ michelangelos-david-reveals-medical-mystery-500-yearslater/4486227002/

8. Kean S. Why doctors should read fiction. https://www. theatlantic.com/health/archive/2018/07/medicine-doctorsfiction $/ 566342 /$

9. Barta P. Personal communication with the author. Oct. 24, 2018.

10. Herman A. A lesson on looking. https://www.ted.com/talks/ amy_herman_a_lesson_on_looking/transcript?language $=e n$

11. Elmer A. artsyforager.com https://www.pinterest.com/pin/ 253257179032528252/ 